\title{
Correction to: Classification of Carotid Artery Intima Media Thickness Ultrasound Images with Deep Learning
}

\section{Serkan Savaş ${ }^{1}$ (ID $\cdot$ Nurettin Topaloğlu ${ }^{2} \cdot$ Ömer Kazcı $^{3} \cdot$ Pınar Nercis Koşar $^{3}$}

Published online: 26 July 2019

(C) Springer Science+Business Media, LLC, part of Springer Nature 2019

\section{Correction to: Journal of Medical Systems}

https://doi.org/10.1007/s10916-019-1406-2

The original article unfortunately contained a mistake.

Figure $2 \mathrm{~b}$ was removed in the article.

The original version has been corrected.

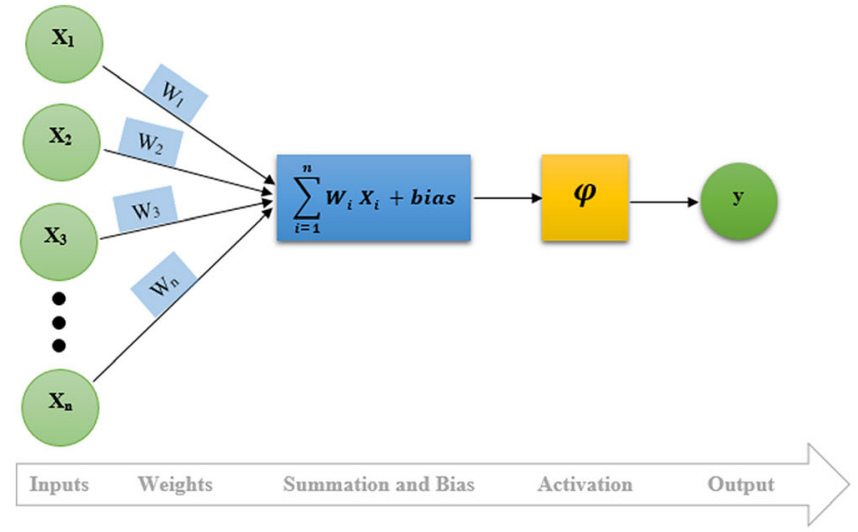

a

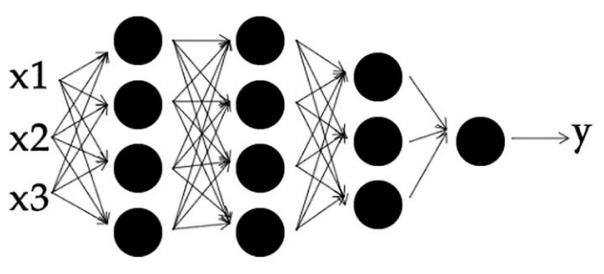

b

Fig. 2 a ANN structure b DNN structure

The online version of the original article can be found at https://doi.org/ 10.1007/s10916-019-1406-2

Serkan Savas

serkan_savas@hotmail.com

1 Faculty of Technology, Computer Engineering Department Ph.D, Gazi University, Ankara, Turkey

2 Faculty of Technology, Computer Engineering Department, Gazi University, Ankara, Turkey

3 Department of Radiology, Ankara Training and Research Hospital, Ankara, Turkey
Publisher's Note Springer Nature remains neutral with regard to jurisdictional claims in published maps and institutional affiliations. 